Volume 9, No.1.5, 2020

International Journal of Advanced Trends in Computer Science and Engineering

Available Online at http://www.warse.org/IJATCSE/static/pdf/file/ijatcse2091.52020.pdf

https://doi.org/10.30534/ijatcse/2020/2091.52020

\title{
Frequency-Reconfigurable Multiband Antenna Based on Pin Switch for Wireless Applications
}

\author{
${ }^{1}$ Ibrahime Hassan Nejdi, ${ }^{2}$ Youssef Rhazi, ${ }^{3}$ Mustapha Ait Lafkih, ${ }^{4}$ Seddik Bri \\ ${ }^{1,2,3}$ Laboratory of Automatics, Energy Conversion and Microelectronics (LACEM), Faculty of Sciences and \\ Technology, Beni-Mellal, Morocco \\ ${ }^{1}$ nejdi.ibrahime.hassan@gmail.com, ${ }^{2}$ rhazi.lastid@gmail.com, ${ }^{3}$ aitlafkihmustapha@yahoo.fr \\ ${ }^{4}$ Electrical Engineering Department, High School of Technology: ESTM Moulay Ismail University, B. P 3103 , \\ Meknes, Morocco, briseddik@gmail.com
}

\begin{abstract}
The design of reconfigurable multiband antenna for wireless applications such as UMTS, T-DMB, LTE, WiMAX, WLAN and WiBro bands applications is presented in this paper. The antenna is made up of four radiating elements which alternately play the role of active or parasitic element. In addition, we chose a reconfigurable antenna with a narrow bandwidth, in order to be able to shift in a radio frequency spectrum also to avoid band interference. This system is qualified to control the S11 by switching the four PIN diodes state while preserving the same structure.
\end{abstract}

Keywords : Reconfigurable antenna, PIN diodes, bandwidth, parasitic element.

\section{INTRODUCTION}

To meet the requirement demanded by modern communications systems, the mobile devices must operate according to different adjustable standards. It is preferable for this purpose that several frequency bands are covered by the antennas. In the literature, several multiband antenna structures are proposed to meet the requirements of development [1-4]. In [1] the authors, present a multiband antenna array with a high gain operating at 3.7, 5.2 and 5.8GHz. In [2], Shruthi G \& Yogesh Kumar show a developed PIFA multiband antenna study. to cover the DCS1800, GSM 900 and WLAN 2.4GHz frequency band. In [3], the authors present a full study to improve an elementary rectangular antenna, to a novel multiband multilayer antenna with the best reflection coefficient and gain. RF switches are used as setting item or signal path selection item, this feature helps to cut the telecommunications systems complexity to get multiband or wideband operation. The reconfigurable antennas are based on the RF switches. In the literature [5-14] a few reconfigurable antenna designs are presented. The authors in [5-8], present some frequency reconfigurable antennas models using VO2 switches. In order to cover the two different frequency bands at 2.7 and $3.5 \mathrm{GHz}$, [5] propose a reconfigurable planar inverted $\mathrm{F}$ antenna (PIFA) / T-shaped monopole antenna with a printed VO2 switch. A reconfigurable network antenna is shown in [6], its radiation pattern is based on a printed VO2 switch. In [10] the authors use L-shape and U-shape radiators to ameliorate the bandwidth and to add supplementary bands, two PIN diodes are used to realize the switching between the main radiator, and the L- and U- shape radiators. Using two PIN switches, the authors in [11] propose a multiband patch antenna realization with a reconfigurable circular polarization, which generates an adjustment of the currents flowing direction on the radiating element, and an adjustment of bidirectional radiation characteristics. To cover the WiMAX, Bluetooth and WLAN bands, the authors of [12] use a bow-tie antenna printed on both substrate sides, using PIN diodes, the authors were able to modify the patch electrical length which leads to an electrically tunable operating ban. By switching of PIN diode state in [13], the authors present a reconfigurable slot-ring patch which may be applied as a unit of a large array. The authors present in [15] the bending effect study of multiband antennas on their resonance frequencies to facilitate the antennas implementation.

In this work, we present a new frequency reconfigurable antenna printed on a FR4_epoxy substrate. The resonators are positioned at an optimal height above the ground and the feed line, to attenuate the reflected waves and the back lobes in the intention of entraining an increase in the antenna gain. In addition, the patch antenna may be implemented with the associated circuit and be away from its effects at the same time. to connect between the resonators and the feed line we use vias. We placed four PIN diode switches between the feed line and the vias, in order to dynamically change the antenna function, thus, each frequency band have its proper feed lines.

\section{ANTENNA DESIGN}

Figure 1 illustrates the proposed antenna structure. The feed line design is taken into account to correspond to a 50 ohms impedance. The proposed antenna consists of four radiators each linked to a feed line by a via, and each feed line is linked to the mainline feed by a PIN switch. Therefore, each PIN switches damping combination generates multiband. In this search, we use two FR4 epoxy 
substrates, the first is resonator support with $0.6 \mathrm{~mm}$ thickness, the second substrate is feed line support with 1.6 mm thickness. The two substrates are distanced by $4.5 \mathrm{~mm}$. This antenna form is designed to achieve a selective multiband response. We design the antenna using the software high-frequency simulation (HFSS). The optimized antenna dimensions are resumed in Table 1.

We use four PIN diodes BAP65-02-115NXP [18] as switches denoted D1, D2, D3 and D4 to configure the antenna so that operate in different frequency bands. According to [18], the diode in the $\mathrm{ON}$ state is equivalent to two capacitors ( $\mathrm{C} 1$ and $\mathrm{C} 2$ ), resistance (Ron) and inductors (L1) in series, while it is equivalent in the OFF state to two capacitors and inductors in series with a resistance (Roff) parallel to the capacitors (Coff). Figure 2 exposes the diodes equivalent scheme. We assume that all PIN diodes used in HFSS simulations are lossless. The anodes of the four diodes are connected to the main feed line, while the cathodes to the parts of feed lines which are linked to the vias. To switch the state of the diodes between "ON" and "OFF", we use a DC bias voltage.

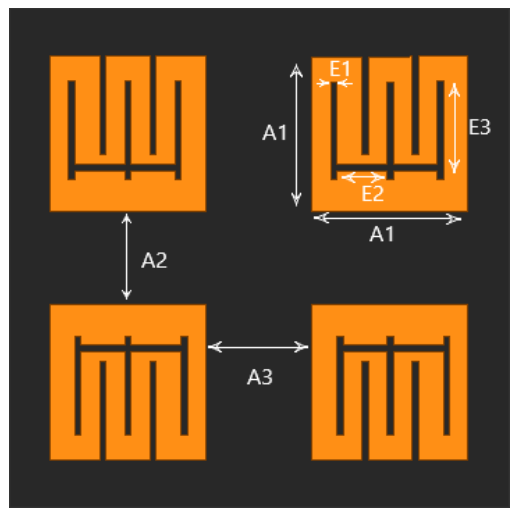

(a)

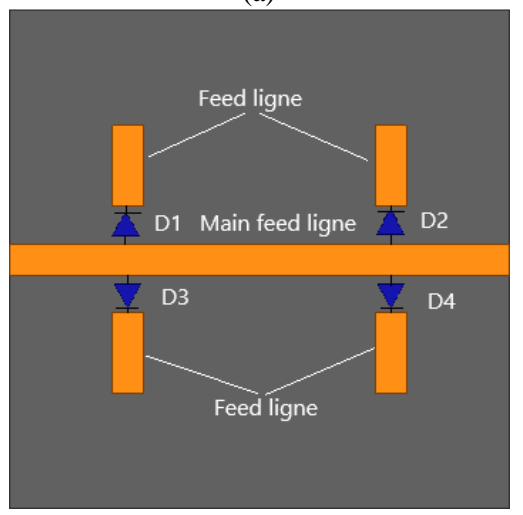

(b)

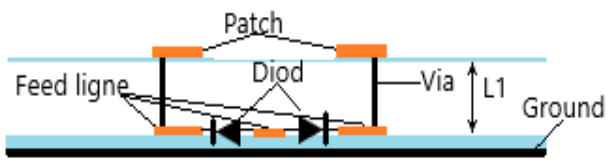

(c)

Figure 1 :The proposed antenna schema (a) Antenna top view (b) Feed line top view (c) Antenna system geometry sees from the side
Table 1: The Proposed Antenna Reconfigurable Key Dimension in $\mathrm{mm}$

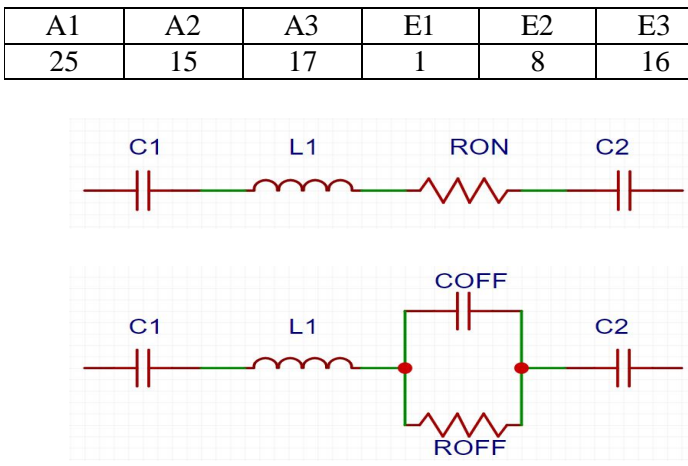

Figure 2: PIN diodes equivalent scheme

\section{ACHIEVED RESULTS AND DISCUSSION}

Employing the reflection coefficient S11 plotted in Figure 3, we studied the frequency reconfigurability. The four PIN diodes offer several possible switching states, but in the symmetry reason, we have studied only nine combinations. By varying the diodes state, the four radiators will connect or disconnect to the main feed line, which leads to the variation in operating frequencies. To facilitate the study and the comparison, for all proposed PIN diode commutation state we have divided the frequency band studied (from 1 to $6.4 \mathrm{GHz}$ ) into five parts. The first part from 1.2 to $1.5 \mathrm{GHz}$ is given by Figure 3 (a), the second part is shown in Figure 3 (b) corresponds to the frequency range 2.2 to $2.8 \mathrm{GHz}$, Figure 3 (c) presents the frequency range between 3.1 and $3.6 \mathrm{GHz}$, while the fourth part from 4.2 to $4.9 \mathrm{GHz}$ is plotted in Figure 3 (d), and finally the fifth part from 5.4 to 6.4 is shown in Figure 3 (e). Whereas we present the results summary of the resonance frequency, reflection coefficient and gain in Table 2.

When we activate the four PIN switches, the four resonators are connected to the feed line, according to Figure 3 and Table 2, we have seven bands which resonate between $1 \mathrm{GHz}$ and $6.4 \mathrm{GHz}$. The reflection coefficient can reach to $-36.95 \mathrm{~dB}$, with gain which achieves $3.53 \mathrm{~dB}$ and bandwidth reach 275.6 MHz. Once D1 D2 and D3 are ON and D4 OFF we get six bands that may reach the reflection coefficient $-38.93 \mathrm{~dB}$, the gain $3.89 \mathrm{~dB}$ and the bandwidth 254.9 MHz. By using the combination D1, D2 are ON and D3, D4 are OFF, we get seven bands with the reflection coefficient which varies between -16.44 and $-30.73 \mathrm{~dB}$, the gain reaches on up to $5.17 \mathrm{~dB}$ and the bandwidth 308.7 MHz. When D1 and D3 are ON and the two PIN diodes D2 and D4 are OFF, we get seven bands with the reflection coefficient which may reach $-34.81 \mathrm{~dB}$ with the maximum gain that reaches $4.72 \mathrm{~dB}$ and bandwidth 213.1 MHz. We get six bands with the reflection coefficient who can attain $36.93 \mathrm{~dB}$, the gain which achieves $2.41 \mathrm{~dB}$ and bandwidth $330.7 \mathrm{MHz}$ when we switch ON D1 and D4 we switch OFF D2 and D3. When we only switch ON D1 we obtain five bands resonant where the reflection coefficient attains $28.08 \mathrm{~dB}$, the gain of $5.48 \mathrm{GHz}$ and the bandwidth 269.7 
MHz. If D2 and D4 are ON and the other two are OFF, four bands are found with the reflection coefficient which achieves $-37.95 \mathrm{~dB}$, the gain $2.58 \mathrm{~dB}$ and the bandwidth 279.8 MHz. When only D2 is ON we get four bands with the reflection coefficient which can get at $-23.89 \mathrm{~dB}$, the gain $2.51 \mathrm{~dB}$ and bandwidth 407.9 MHz. We get four bands with the reflection coefficient which reach $-25.47 \mathrm{~dB}$, the gain 2.91dB and the bandwidth 273.3 MHz if the four PIN switches are OFF. We notice that even if all the diodes are $\mathrm{OFF}$, we have radiation with a gain that may reach $2.91 \mathrm{~dB}$, this is due to the fact that the feed line plays the role of the resonator and that the four resonators play the parasite role.

The design proposed in this article is capable of producing several operating bands. Table 3 present the operating bands according to the PIN switch state. From results presented in Figure 3 and Table 3, we notice that by switching the four PIN diodes state, the frequency bands [1.30 - 1.35] GHz, [1.41 - 1.46] GHz, [2.24 - 2.45] GHz, [2.49 - 2.56] GHz, [2.67 - 2.77] GHz, [3.16 - 3.48] GHz, [4.32 - 4.59] GHz, [4.65 - 4.83] GHz and [5.49 - 6.14] GHz are covered. Table 4 summarizes the different combinations of diodes possible to cover the operating bands. For example, according to table 4, the band [2.49 - 2.56] $\mathrm{GHz}$ is covered by summing the bands resulting from the following four combinations, all PIN diodes are ON, the three diodes D1, D2 and D3 are ON and D4 OFF, the third is the combination D1 and D3 are On and D2 and D4 are OFF and finally when D1 ON and the other three are in the OFF state. Therefore, by switching the PIN switches state, the antenna is appropriate for wireless applications such as the universal mobile telecommunications system (UMTS), Terrestrial Digital Multimedia Broadcasting (T-DMB), Bluetooth, Long Term Evolution band (LTE), Worldwide Interoperability for Microwave Access (WiMAX), it can also cover wireless network (WLAN), Wireless Broadband (WiBro) applications.

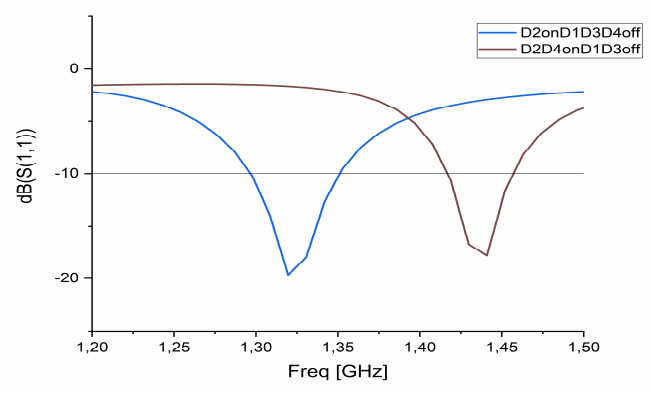

(a)

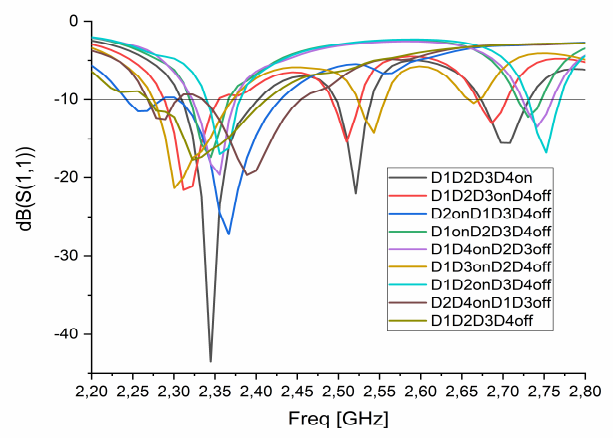

(b)

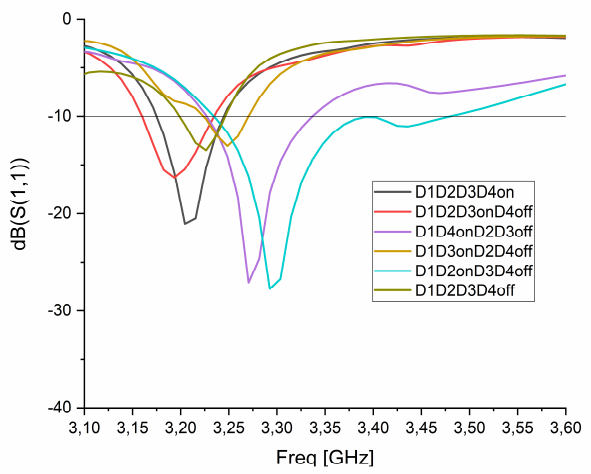

(c)

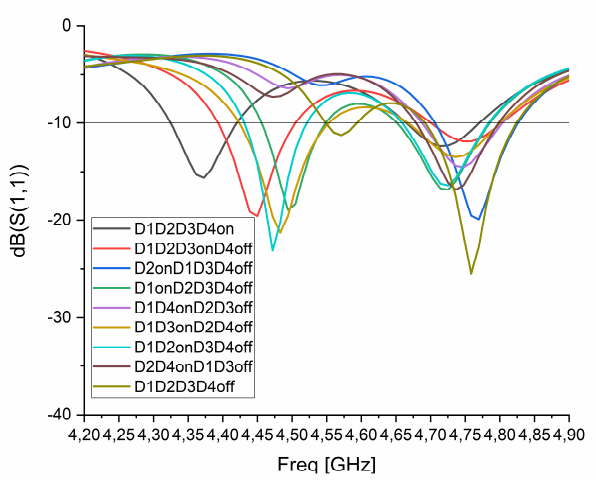

(d)

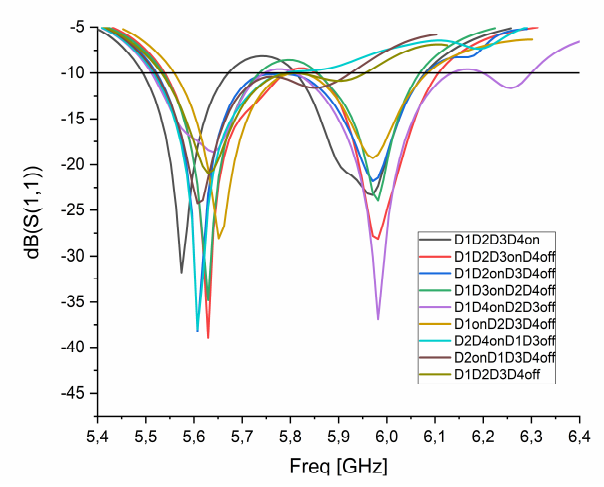

(e)

Figure 3: The simulated antenna reflection coefficient at the nine switch modes for the frequency range (a) from 1.2 to $1.5 \mathrm{GHz}$ (b) from 2.2 to $2.8 \mathrm{GHz}$ (c) from 3.1 to $3.6 \mathrm{GHz}$ (d) from 4.2 to $4.9 \mathrm{GHz}$ (e) from 5.4 to $6.4 \mathrm{GHz}$

By viewing the gains simulation results presented in Table 2, we note that the antenna gains in the band [1.30 $1.35] \mathrm{GHz}$ is -0.98 , for the second band [1.41 - 1.46] $\mathrm{GHz}$ of $-1.76 \mathrm{~dB}$, for the third [2.24 -2.45$] \mathrm{GHz}$ the gain goes from 1.62 to $2.81 \mathrm{~dB}$. It goes from -0.62 to $-0.15 \mathrm{~dB}$ in the fourth band [2.49 - 2.56] GHz, also from -0.095 to $2.45 \mathrm{~dB}$ in the fifth band [2.67 - 2.77]. In the sixth band [3.16 - 3.48] it goes from 0.57 to $4.66 \mathrm{GHz}$, and it varies from 2.68 to $5.17 \mathrm{~dB}$ for the seventh band [4.32 - 4.59] GHz. In the eighth band [4.65 - 4.83] $\mathrm{GHz}$ we have the gain variation margin 
between 0.67 and $2.00 \mathrm{~dB}$. Finally, in the ninth band [5.49 6.14] $\mathrm{GHz}$ the gain goes from -0.25 to $2.91 \mathrm{~dB}$.

For all PIN diodes combinations, the reconfigurable antenna radiation patterns in the main planes $\mathrm{x}-\mathrm{z}$ and $\mathrm{y}-\mathrm{z}$ are plotted in Figure 4. Figure 4 (a) presents the radiation diagram when all the diodes are ON. Figure 4 (b) shows the diagram where D4 is OFF and the other PIN diodes are ON. Figure 4 (c) show the radiation pattern form when we use the combination, D1 and D2 are ON and D3 and D4 are OFF. Whereas, when the PIN switch D1 and D3 are ON and the others are OFF, the diagram is presented in Figure 4 (d). For the diagram presented by Figure 4 (e), we turn OFF D2 and D3 and the other two are ON. When only D1 is ON the diagram is shown in Figure 4 (f). If D2 and D4 are ON and D1 and D3 are OFF we present it in Figure $4(\mathrm{~g})$. When only the switch D2 is ON, the diagram is presented in Figure 4 (h), finally, if all the PIN diodes are OFF, we present it in Figure 4 (i).
We note that in the $\mathrm{H}$ plane, the radiation patterns of the majority of the frequency bands are omnidirectional for example in Figure 4 (b) at frequency $3.19 \mathrm{GHz}$ and Figure 4 (g) at frequency $1.44 \mathrm{GHz}$ we have non-directive radiation it is equal in all directions and almost omnidirectional for some bands. On the E plane, we notice that the radiation patterns in the most lower frequency bands are omnidirectional as at frequency $2.52 \mathrm{GHz}$ in Figure 4 (a) and at frequency $2.75 \mathrm{GHz}$ in Figure 4 (c), and they remain roughly quasi omnidirectional in the other bands, this produce owing to the FR-4 material quality which does not work correctly in the elevated operating frequencies. Also, we note in Figure $4(\mathrm{~g})$ precisely at the frequency $1.44 \mathrm{GHz}$ a shape of " 8 " lead to a bidirectional pattern. Thus, the proposed patch antenna is highly competitive for applications in wireless applications.

Table 1:Summarized Results of The Proposed Antenna

\begin{tabular}{|c|c|c|c|c|c|c|}
\hline \multicolumn{4}{|c|}{$\begin{array}{l}\text { State Operation of PIN } \\
\text { Diode }\end{array}$} & \multirow[t]{2}{*}{$\begin{array}{l}\text { Resonance frequency } \\
\text { (GHz) }\end{array}$} & \multirow[t]{2}{*}{ Reflection coefficient (dB) } & \multirow[t]{2}{*}{ Gain (dB) } \\
\hline D1 & D2 & D3 & D4 & & & \\
\hline $\mathrm{ON}$ & ON & ON & ON & $\begin{array}{l}2.35,2.52,2.71,3.20,4.37 \\
5.57,5.97\end{array}$ & $\begin{array}{l}-36.95,-22.03,-15.55,-21.05, \\
-15.636,-31.81,-23.30\end{array}$ & $\begin{array}{l}1.79,-0.212,2.45,3.53, \\
2.68,2.23,2.16\end{array}$ \\
\hline $\mathrm{ON}$ & ON & $\mathrm{ON}$ & OFF & $\begin{array}{l}2.31,2.51,3.19,4.45,5.63 \\
5.97\end{array}$ & $\begin{array}{l}-21.58,-15.39,-16.33,-19.57, \\
-38.93,-27.80\end{array}$ & $\begin{array}{l}2.43,-0.15,2.74,3.89,2.39, \\
1.17\end{array}$ \\
\hline $\mathrm{ON}$ & ON & OFF & OFF & $\begin{array}{l}2.36,2.75,3.29,4.47,4.73 \\
5.62,5.97\end{array}$ & $\begin{array}{l}-16.97,-16.78,-27.79,-23.10, \\
-16.44,-30.73,-21.81\end{array}$ & $\begin{array}{l}2.45,-0.095,4.66,5.17, \\
1.14,2.85,0.52\end{array}$ \\
\hline $\mathrm{ON}$ & OFF & ON & OFF & $\begin{array}{l}\text { 2.30, } 2.54,3.25,4.48,4.74 \text {, } \\
5.63,5.98\end{array}$ & $\begin{array}{l}-21.35,-14.5,-13.06,-21.29 \\
-13.53,-34.81,-23.93\end{array}$ & $\begin{array}{l}1.62,-0.62,3.30,4.72, \\
1.34,2.66,-0.25\end{array}$ \\
\hline $\mathrm{ON}$ & OFF & OFF & $\mathrm{ON}$ & $\begin{array}{l}2.36,2.74,3.27,4.74,5.64, \\
5.98\end{array}$ & $\begin{array}{l}-19.67,-13.49,-27.13,- \\
14.39,-18.62,-36.93\end{array}$ & $\begin{array}{l}2.41,1.59,1.60,2.00,0.95 \\
-0.05\end{array}$ \\
\hline $\mathrm{ON}$ & OFF & OFF & OFF & $2.34,4.49,4.71,5.65,5.97$ & $\begin{array}{l}-17.40,-18.92,-16.75,- \\
28.08,-19.27\end{array}$ & $1.92,5.48,1.34,2.65,0.16$ \\
\hline OFF & ON & OFF & ON & $1.44,2.40,4.73,5.61$ & $-17.81,-19.17,-16.89,-37.95$ & $-1.76,2.13,0.9,2.58$ \\
\hline OFF & $\mathrm{ON}$ & OFF & OFF & $1.32,2.37,4.77,5.62$ & $-19.67,-27.21,-19.92,-23.89$ & $-0.98,2.81,0.67,2.51$ \\
\hline OFF & OFF & OFF & OFF & $2.32,3.22,4.76,5.63$ & $-17.7,-13.5,-25.47,-20.98$ & $2.69,0.57,0.68,2.91$ \\
\hline
\end{tabular}


Ibrahime Hassan Nejdi et al., International Journal of Advanced Trends in Computer Science and Engineering, 9(1.5), 2020, 138 - 146

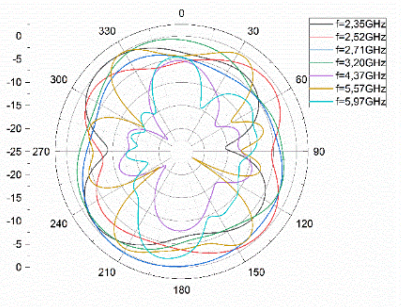

E plan

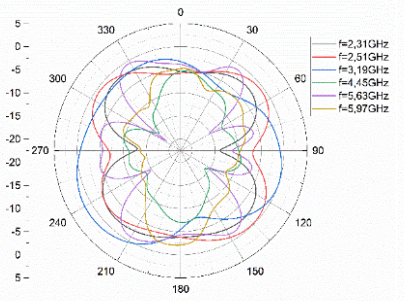

E plan

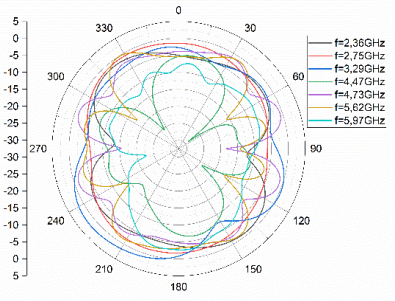

E plan

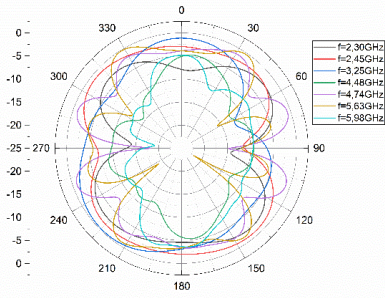

E plan

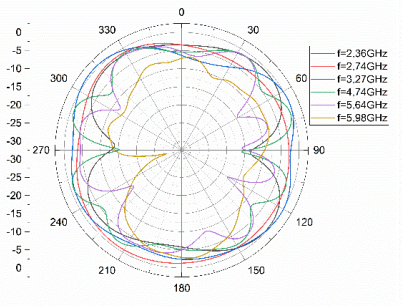

E plan

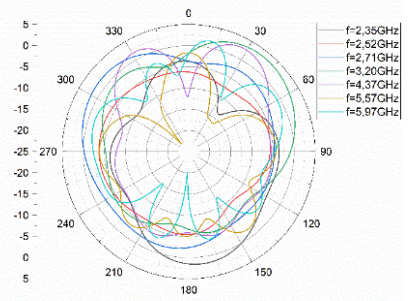

B plan

(a)

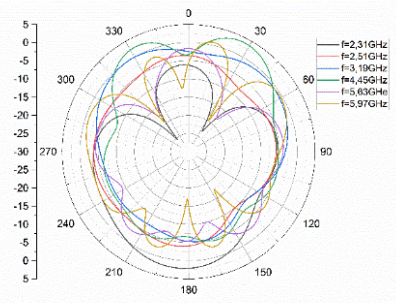

B plan

(b)

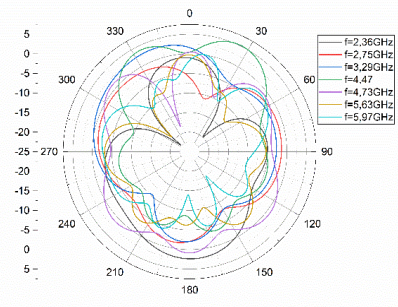

(c)

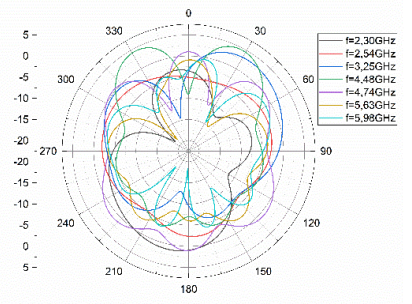

B plan

(d)

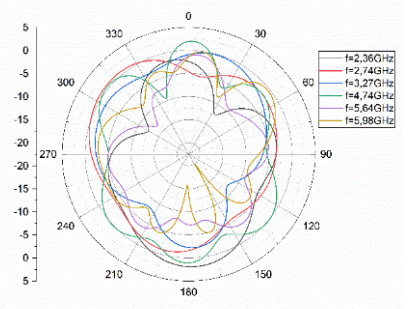

B plan

(e) 


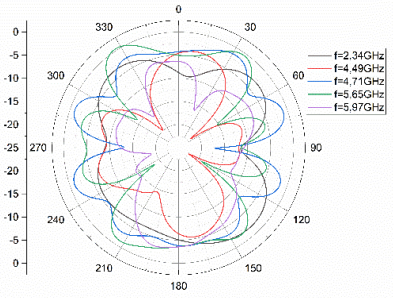

E plan

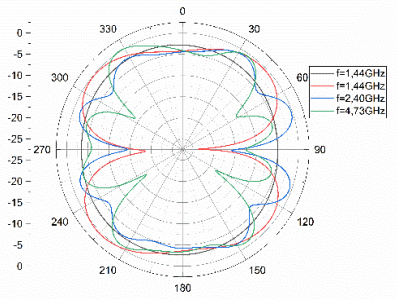

E plan

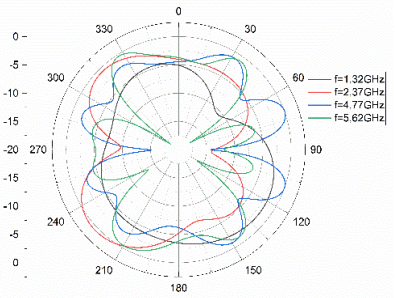

Eplan

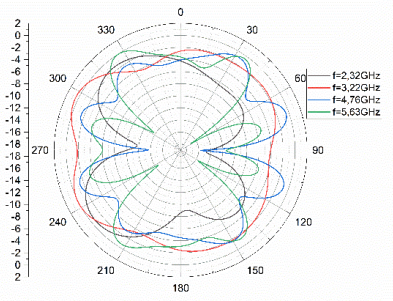

E plan

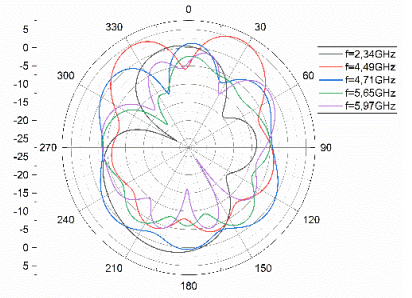

B plan

(f)

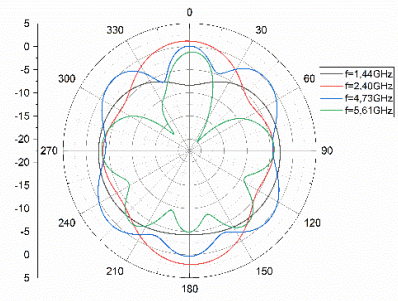

B plan

(g)

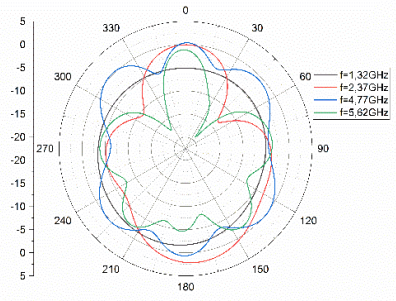

B plan

(h)

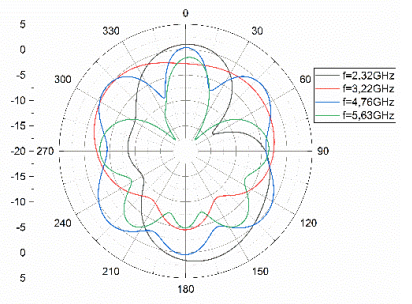

B plan

(i)

Figure 2The reconfigurable antenna radiation patterns in E plane and H plane (a) D1D2D3D4 ON (b) D1D2D3 ON D4 OFF (c) D1D2 ON D3D4 OFF (d) D1D3 ON D2D4 OFF (e) D1D4 ON D2D3 OFF (f) D1 ON D2D3D4 OFF (g) D2D4 ON D1D3 OFF (h) D2 ON D1D3D4 OFF (i) D1D2D3D4 OFF

We give in Table 5 the comparison between the patch antennas available in the literature and the antenna proposed in this work. It is clear that the proposed patch antenna in this work shows in terms of a number of a PIN diode and band great competitiveness. The authors of [16] employ four diodes and they obtain two frequencies, while the antenna of [17] uses six diodes and presents the smallest size, but it is limited to four bands. The antenna that we propose with using four diodes presents fifty bands.
Table 1. Operating bands according to PIN switch state

\begin{tabular}{|c|c|c|c|c|}
\hline \multicolumn{3}{|c|}{$\begin{array}{c}\text { State Operation of PIN } \\
\text { Diodes }\end{array}$} & \multirow{2}{*}{ Operating Bands (GHz) } \\
\hline D1 & D2 & D3 & D4 & \\
\hline ON & ON & ON & ON & $\begin{array}{l}{[2.30,2.40],[2.49,2.54],[2.67,} \\
2.73],[3.17,3.24],[4.32,4.42], \\
{[5.49,5.67],[5.81,6.08]}\end{array}$ \\
& & & & \\
\hline
\end{tabular}


Ibrahime Hassan Nejdi et al., International Journal of Advanced Trends in Computer Science and Engineering, 9(1.5), 2020, 138 - 146

\begin{tabular}{|c|c|c|c|c|}
\hline ON & ON & ON & OFF & $\begin{array}{l}{[2.28,2.35],[2.49,2.52],[3.16,} \\
3.23],[4.39,4.50],[5.53,5.79], \\
{[5.85,6.10]}\end{array}$ \\
\hline ON & ON & OFF & OFF & $\begin{array}{l}{[2.33,2.38],[2.73,2.77],[3.23,} \\
3.48],[4.43,4.52],[4.65,4.78] \text {, } \\
{[5.51,5.77],[5.77,6.08]}\end{array}$ \\
\hline ON & OFF & ON & OFF & $\begin{array}{l}{[2.27,2.37],[2.52,2.56],[3.22,} \\
3.27],[4.42,4.59],[4.66,4.80], \\
{[5.53,5.73],[5.85,6.06]}\end{array}$ \\
\hline $\mathrm{ON}$ & OFF & OFF & ON & $\begin{array}{l}{[2.32,2.37],[2.72,2.76],[3.22,} \\
3.33],[4.68,4.80],[5.51,5.74] \text {, } \\
{[5.80,6.14]}\end{array}$ \\
\hline ON & OFF & OFF & OFF & $\begin{array}{l}{[2.31,2.36],[4.45,4.54],[4.65,} \\
4.78],[5.55,5.81],[5.81,6.08]\end{array}$ \\
\hline $\mathrm{OFF}$ & ON & OFF & ON & $\begin{array}{l}{[1.41,1.46],[2.33,2.45],[4.67,} \\
4.79],[5.51,5.79]\end{array}$ \\
\hline OFF & ON & OFF & OFF & $\begin{array}{l}{[1.30,1.35],[2.30,2.43],[4.70,} \\
4.83],[5.51,5.92]\end{array}$ \\
\hline OFF & OFF & OFF & OFF & $\begin{array}{l}{[2.24,2.41],[3.19,3.24],[4.69,} \\
4.82],[5.53,5.80]\end{array}$ \\
\hline
\end{tabular}

\begin{tabular}{|c|c|c|c|c|}
\hline \multirow[t]{4}{*}{ [2.49-2.56] } & $\mathrm{ON}$ & ON & $\mathrm{ON}$ & ON \\
\hline & $\mathrm{ON}$ & $\mathrm{ON}$ & $\mathrm{ON}$ & OFF \\
\hline & ON & OFF & ON & OFF \\
\hline & $\mathrm{ON}$ & OFF & OFF & OFF \\
\hline \multirow[t]{3}{*}{ [2.67 - 2.77] } & ON & ON & ON & $\mathrm{ON}$ \\
\hline & $\mathrm{ON}$ & ON & OFF & OFF \\
\hline & $\mathrm{ON}$ & OFF & OFF & ON \\
\hline \multirow[t]{4}{*}{ [3.16 - 3.48$]$} & $\mathrm{ON}$ & ON & ON & ON \\
\hline & $\mathrm{ON}$ & $\mathrm{ON}$ & ON & OFF \\
\hline & $\mathrm{ON}$ & $\mathrm{ON}$ & OFF & OFF \\
\hline & $\mathrm{ON}$ & OFF & ON & OFF \\
\hline \multirow[t]{4}{*}{ [4.32 - 4.59] } & $\mathrm{ON}$ & ON & $\mathrm{ON}$ & ON \\
\hline & $\mathrm{ON}$ & $\mathrm{ON}$ & $\mathrm{ON}$ & OFF \\
\hline & $\mathrm{ON}$ & ON & OFF & OFF \\
\hline & $\mathrm{ON}$ & OFF & ON & OFF \\
\hline \multirow[t]{7}{*}{ [4.65 - 4.83] } & $\mathrm{ON}$ & $\mathrm{ON}$ & OFF & OFF \\
\hline & $\mathrm{ON}$ & OFF & $\mathrm{ON}$ & OFF \\
\hline & $\mathrm{ON}$ & OFF & OFF & ON \\
\hline & $\mathrm{ON}$ & OFF & OFF & OFF \\
\hline & OFF & $\mathrm{ON}$ & OFF & ON \\
\hline & OFF & $\mathrm{ON}$ & $\mathrm{OFF}$ & OFF \\
\hline & OFF & OFF & OFF & OFF \\
\hline \multirow[t]{3}{*}{ [5.49-6.14] } & $\mathrm{ON}$ & $\mathrm{ON}$ & $\mathrm{ON}$ & ON \\
\hline & $\mathrm{ON}$ & ON & ON & OFF \\
\hline & ON & $\mathrm{ON}$ & OFF & OFF \\
\hline
\end{tabular}

Table 2. Combinations of diodes to cover the operating bands

\begin{tabular}{|c|c|c|c|c|}
\hline \multirow[t]{2}{*}{ Operating bands (GHz) } & \multicolumn{4}{|c|}{$\begin{array}{c}\text { State Operation of PIN } \\
\text { Diodes }\end{array}$} \\
\hline & D1 & D2 & D3 & D4 \\
\hline [1.30 - 1.35] & OFF & $\mathrm{ON}$ & OFF & OFF \\
\hline [1.41 - 1.46] & OFF & $\mathrm{ON}$ & OFF & $\mathrm{ON}$ \\
\hline \multirow[t]{9}{*}[2.24-2.45]{} & $\mathrm{ON}$ & $\mathrm{ON}$ & $\mathrm{ON}$ & $\mathrm{ON}$ \\
\hline & $\mathrm{ON}$ & $\mathrm{ON}$ & $\mathrm{ON}$ & OFF \\
\hline & $\mathrm{ON}$ & $\mathrm{ON}$ & OFF & OFF \\
\hline & $\mathrm{ON}$ & OFF & $\mathrm{ON}$ & OFF \\
\hline & $\mathrm{ON}$ & OFF & OFF & $\mathrm{ON}$ \\
\hline & $\mathrm{ON}$ & OFF & OFF & OFF \\
\hline & OFF & $\mathrm{ON}$ & OFF & $\mathrm{ON}$ \\
\hline & OFF & $\mathrm{ON}$ & OFF & OFF \\
\hline & OFF & OFF & OFF & OFF \\
\hline
\end{tabular}




\begin{tabular}{|l|l|l|l|l|}
\hline \multirow{5}{*}{} & ON & OFF & ON & OFF \\
\cline { 2 - 5 } & ON & OFF & OFF & ON \\
\hline \multirow{7}{*}{ ON } & OFF & OFF & OFF \\
\cline { 2 - 5 } & OFF & ON & OFF & ON \\
\cline { 2 - 5 } & OFF & ON & OFF & OFF \\
\cline { 2 - 5 } & OFF & OFF & OFF & OFF \\
\hline
\end{tabular}

Table 3. Comparison Between Proposed Antenna and Reported Antennas

\begin{tabular}{|c|c|c|c|c|}
\hline Ref. & $\begin{array}{c}\text { Size } \\
(\mathbf{m m 2})\end{array}$ & $\begin{array}{c}\text { Number } \\
\text { of } \\
\text { switches }\end{array}$ & $\begin{array}{c}\text { Switches } \\
\text { system }\end{array}$ & Bands \\
\hline$[16]$ & $40.4 \times 37.8$ & 4 & $\begin{array}{c}\text { PIN } \\
\text { diode }\end{array}$ & 2 \\
{$[17]$} & $30 \times 30$ & 6 & $\begin{array}{c}\text { PIN } \\
\text { diode }\end{array}$ & 4 \\
Proposed & $80 \times 80$ & 4 & $\begin{array}{c}\text { PIN } \\
\text { diode }\end{array}$ & 50 \\
\hline
\end{tabular}

\section{CONCLUSION}

In this letter, we have proposed a multiband antenna reconfigurable in frequency, based on PIN diodes. Its structure let it capable to be implemented with the associated circuit on the same dielectric substrate and at the same time be far from its effects, which allows the minimization of production costs. The radiating elements of the antenna may alternatively be played the role of the parasitic or active element when we modify the PIN diodes state. This operating principle has allowed us to generate several bands resonating between frequencies 1 and 6.4 $\mathrm{GHz}$. Therefore, the proposed design is suitable for wireless applications such as UMTS, T-DMB, LTE, WiMAX, WLAN and WiBro with good gain and radiation characteristics are offered at their operational bands.

\section{REFERENCES}

[1] K. Fertas, H. Kimouche, M. Challal, H. Aksas and R. Aksas, "Multiband Microstrip Antenna Array for Modern Communication Systems", 2015 4th International Conference on Electrical Engineering (ICEE), IEEE Xplore 25 February 2016.

[2] Shruthi G and Yogesh Kumar Choukiker, "Multiband PIFA Antenna for Mobile Handheld Devices",
Citation information:

DOI

10.1109/INCAP.2018.8770948.

[3] Ibrahime Hassan Nejdi, Youssef Rhazi, Mustapha Ait Lafkih, Seddik Bri, "Development of Rectangular Multilayer Antennas for Several Bands", European Journal of Scientific Research ISSN 1450-216X / 1450202X Vol. 153 No 1 May, 2019, pp. 91-104.

[4] Pir Saadullah Shah, Shahryar Shafique Qureshi, Muhammad Haneef, Sohail Imran Saeed, "Size

Reduction and Performance Enhancement of Pi Shaped Patch Antenna using Superstrate Configuration", Vol. 10, No. 5, 2019, (IJACSA) International Journal of Advanced Computer Science and Applications.

[5] Zhen Su, Mohammad Vaseem, Shuai Yang,Weiwei Li, Kirill Klionovski, Atif Shamim, "Fully Printed VO2 Switch Based Reconfigurable PIFA / T-shaped Monopole Antenna", 2018 18th International Symposium on Antenna Technology and Applied Electromagnetics (ANTEM), Citation information: DOI 10.1109/ANTEM.2018.8572855.

[6] Zhen Su, Mohammad Vaseem, Weiwei Li, Shuai Yang, Atif Shamim, "Additively Manufactured Frequency/Radiation Pattern Reconfigurable Antenna Based on Monolithically Printed VO2 Switch", 2019 13th European Conference on Antennas and Propagation (EuCAP), Date Added to IEEE Xplore 20 June 2019, INSPEC Accession Number 18760050.

[7] D. E. Anagnostou, G. Goussetis, D. Torres, and Nelson Sepulveda, "Ultra-Fast Reconfigurable Antennas with Phase Change Materials", in Proc. Int. Workshop on Antenna Technology (iWAT), Athens, Greece, March 2017, pp. 40-43.

[8] L. Huitema, A. Crunteanu, H. Wong, and E. Arnaud, "Highly integrated VO2-based tunable antenna for millimeter-wave applications", Applied Physics Letters, vol. 11, 2017.

[9] Zhenghang Nie, Huiqing Zhai, Member,IEEE, Longhua Liu, Jiaxu Li, Diwei Hu, and Junhao Shi, "A DualPolarized Frequency-Reconfigurable Low-Profile Antenna with Harmonic Suppression for 5G Application", IEEE Antennas and Wireless Propagation Letters ( Volume: 18 , Issue: 6, June 2019 ), Date of Publication 25 April 2019, DOI: 10.1109/LAWP.2019.2913170.

[10] Hattan F. Abutarboush IEEE Member and A. Shamim IEEE Senior Member,"A Reconfigurable Inkjet Printed Antenna on Paper Substrate for Wireless Applications", IEEE Antennas and Wireless Propagation Letters (Volume 17, Issue 9, Sept. 2018), 31 July 2018, DOI 10.1109/LAWP.2018.2861386.

[11] Tu Tuan Le, Han-Young Park and Tae-Yeoul Yun, "Simple Reconfigurable Circularly Polarized Antenna at Three Bands", Sensors 2019, 19, 2316; doi:10.3390/s19102316.

[12] Tong Li, Huiqing Zhai Member IEEE, Xin Wang, Long Li Senior Member IEEE, and Changhong Liang Senior 
Member IEEE, "Frequency-Reconfigurable Bow-Tie Antenna for Bluetooth, WiMAX, and WLAN Applications", IEEE Antennas and Wireless Propagation Letters ( Volume: 14 ), Page(s) 171 - 174, DOI: 10.1109/LAWP.2014.2359199, Date of publication 19 September 2014.

[13] Mahmoud Shirazi Student Member, IEEE, Junyi Huang Student member IEEE, Tianjiao Li Student member IEEE and Xun Gong Senior Member IEEE, "A Switchable-Frequency Slot-Ring Antenna Element for Designing a Reconfigurable Array", IEEE Antennas and Wireless Propagation Letters (Volume 17, Issue: 2, Feb. 2018), DOI: 10.1109/LAWP.2017.2781463, Page(s): 229 - 233.

[14] Manoj Kumar Garg, Jasmine Saini,"Multi-Band and Multi-Parameter Reconfigurable Slotted Patch Antenna with Embedded Biasing Network", Vol. 10, No. 10, 2019, (IJACSA) International Journal of Advanced Computer Science and Applications.

[15] Ibrahime Hassan Nejdi, Youssef Rhazi, Mustapha Ait Lafkih, Seddik Bri, "Rectangular Three Band Antenna Bending Effect", 2019 7th Mediterranean Congress of Telecommunications (CMT), DOI: 10.1109/CMT.2019.8931335, Date of publication in IEEE Xplore16 December 2019.

[16] Pawan Kumar, Student Member, IEEE, Santanu Dwari, Member, IEEE, Rohit Kumar Saini, and Mrinal Kanti Mandal, Senior Member, IEEE, " Dual-Band DualSense Polarization Reconfigurable Circularly Polarized Antenna", IEEE Antennas and Wireless Propagation Letters ( Volume: 18, Issue: 1, Jan. 2019 ), Page(s): 64 - 68, DOI: 10.1109/LAWP.2018.2880799, Date of Publication: 12 November 2018.

[17] Youcef Braham Chaouche, Farid Bouttout, Idris Messaoudene, Lionel Pichon, Massinissa Belazzoug,and Farouk Chetouah, "Design of reconfigurable fractal antenna using pin diode switch for wireless applications", 2016 16th Mediterranean Microwave Symposium (MMS), Electronic ISSN: 2157-9830, DOI: 10.1109/MMS.2016.7803852, Date Added to IEEE Xplore: 05 January 2017

[18] A. El Fatimi, S. Bri, and A. Saadi, "Reconfigurable Ultra Wideband to Narrowband Antenna for Cognitive Radio Applications Using PIN Diode", TELKOMNIKA (Telecommunication Computing Electronics and Control), vol. 18, no. 6, pp. 2807-2814, 2020. 